\title{
Simultaneous Interpreting: Characteristic of Autonomic Provision of Extreme Cognitive Loads
}

DOI: $10.17691 / \mathrm{stm} 2019.11$ 1.15

Received Noyember 12, 2018

T.V. Chernigovskaya, DSc, Corresponding Member of the Russian Academy of Education,

Head of the Department of the Problems of Natural and Humanitarian Sciences Convergence; Head of the Laboratory for Cognitive Research, Faculty of Liberal Arts and Sciences ${ }^{1}$;

I.S. Parina, PhD, Associate Professor, Department of Theory and Practice

of the German Language and Translation;

S.V. Alekseeva, PhD, Researcher, Laboratory for Cognitive Research, Faculty of Liberal Arts and Sciences';

A.A. Konina, Junior Researcher, Laboratory for Cognitive Research, Faculty of Liberal Arts and Sciences";

PhD Student?

D.K. Urich, PhD Student;

Yu.O. Mansurova, PhD Student, Department of Psychophysiology ${ }^{5}$;

S.B. Parin, DSc, Head of Interdepartmental Laboratory of Cognitive Psychophysiology ${ }^{5}$

${ }^{1}$ Saint Petersburg State University, 7/9 Universitetskaya Naberezhnaya, Saint Petersburg, 199034, Russia;

${ }^{2}$ Linguistics University of Nizhny Novgorod, 31a Minina St., Nizhny Novgorod, 603155, Russia;

${ }^{3}$ University of Helsinki, P.O. Box 3, Fabianinkatu 33, Helsinki, 00014, Finland;

${ }^{4}$ Institute for Bioengineering of Catalonia, Baldiri Reixac 10-12, Barcelona, 08028, Spain;

${ }^{5}$ National Research Lobachevsky State University of Nizhny Novgorod, 23 Prospekt Gagarina, Nizhny Novgorod,

603950, Russia

Simultaneous interpreting is one of the most comprehensive and energy-consuming types of cognitive activity. To work successfully, a simultaneous interpreter must have a specific functional state. The aim of our study was to find out the basic mechanisms of this functional state, the effect of the simultaneous interpreting on cognitive function changes, and the main factors influencing the degree of the regulatory systems strain.

Materials and Methods. 33 individuals participated in the study: 22 linguists specially trained in simultaneous translation composed the experimental group and 11 language-qualified people having no skills of simultaneous translation represented the control group. In compliance with the study design, the measurements were performed under the conditions similar to the real work of simultaneous interpreters: the participants working in succession performed professional tasks: shadowing in the native and foreign languages (German and English), simultaneous interpretation of the reports from the native language to the foreign, and vice versa. The interpreters were psychologically tested using ApWay.ru Web platform before and after the performance on the professional tasks: computer campimetry, test for a simple sensorimotor activity, Stroop test, and test for emotional disadaptation level. Cardiointervalogram was telemetrically recorded during the entire experiment.

Results. Some specific aspects of autonomic provision of simultaneous interpreting have been unraveled. A significantly greater tension of the autonomic regulation is manifested by the simultaneous interpreters compared to the control group. It was most prominent when translation was done from the foreign language. The total level of stress during the performance on the linguistic tasks appeared to be higher in the control group. In the simultaneous interpreters, in contrast to the control group, there was registered a high activity level of the sympathetic and parasympathetic systems and a marked integration of the cardiac rhythm regulation circuits over the entire period of performing the linguistic tasks. The psychological tests have demonstrated a significantly more confident cognitive control relative to the control group. Thus, a specific functional system has been formed in the simultaneous interpreters providing a successful interaction of various information images (or codes) and consolidation of autonomic and cognitive resources during the performance on professional tasks. Lack of the necessary skills and, consequently, of the task-oriented functional system in the participants of the control group resulted in the enhancement of the non-specific (less effective) stress response.

Key words: simultaneous interpreting; cognitive control; cognitive activity; autonomic provision of simultaneous interpreting.

\section{Introduction}

Simultaneous interpreting is one of the most extreme and energy-consuming types of cognitive activity [1]. It is difficult to conceive a more adequate natural model of an intense and exhausting cognitive load. Naturally, a great deal of investigations has been devoted to the process of simultaneous interpreting using linguistic

Corresponding author: Sergey B. Parin, e-mail: parins@mail.ru 
and physiological (for example, PET, fMRI, EEG, pupillometry, measurements of the pulse, arterial pressure, and electrodermal activity, etc.) methods [2-6].

Preliminary results showing a high level of strain during simultaneous interpreting have been obtained by us in the pilot study [7] using a small sample of simultaneous interpreters. A lot of questions remained without answers. For instance, the results of this investigation allowed us to suppose that a specific functional state is required for successful work of a simultaneous interpreter. Therefore, it is necessary to find out the basic mechanisms of this functional state. Of special interest are the type of the activity (for example, translation from the source language to the target one or, vice versa, from the target to the source language) that exerts the greatest tension upon the regulatory systems and the changes in the cognitive functions that may be caused by simultaneous interpreting. Solution of these problems became the aim of this in-depth study.

\section{Material and Methods}

To assess objectively the functional state dynamics of the simultaneous interpreters, the technology of event-related telemetry of the heart rate (ERT HR) was used [8]. This technology integrates the ApWay.ru Web platform for the controlled activation of primary cognitive functions and the StressMonitor.ru Internet application on the basis of cogni-nn.ru to collect telemetry data on the functional state and for stress detection. The advantage of this technology consists in the possibility of on-line detecting early biomarkers of extreme conditions without mobility restrictions and attracting participants' attention to the process of measurements.

87 individuals divided into two groups (experimental and control) participated in our experiments. The data about 33 participants, whose cardiointervalograms contained the artifacts the amount of which did not exceed $10 \%$ of the total recording duration, have been chosen for statistical processing and discussion of the results. The experimental group (pro) was composed of 22 linguists (17 women and 5 men aged $20-34$ years) trained for simultaneous interpretation and experienced in this kind of work. The control group $(n=11,8$ women and 3 men of the same age range) included languagequalified people having no skills in simultaneous translation.

The experiments were designed under the conditions similar to the real work of simultaneous interpreters (Figure 1).

Slightly revised texts of the reports delivered at the World Ecological Forum were used as a stimulus material presented to the interpreters in the form of video tracks recorded by the native speakers. Each presentation lasted 5-6 min. Participants changing in succession performed professional tasks: shadowing the text in the native (Russian - N_shad) and foreign (German or English - F_shad) languages, and simultaneous translation of the reports from the native to the foreign (N_simul) languages and vice versa (F_simul).

The interpreters were psychologically tested using ApWay platform before and after the performance on the professional tasks: computer campimetry, test for a simple sensorimotor activity, Stroop test. A projective test for emotional disadaptation level provided a subjective assessment of the functional state [9]. Audio recording of the professional task performance was done for further linguistic expert evaluation.

Cardiointervalograms (ERT HR) were recorded during the entire experimental period. The native dynamics of $\mathrm{R}-\mathrm{R}$ intervals and calculated indicators were registered in the participants: total power of the heart rate variability spectrum (TP), spectrum power in the high frequency range (HF is the characteristic of the parasympathetic contour activity of the autonomic regulation), spectrum power in the low frequency range (LF is the characteristic of the sympathetic contour activity of the autonomic regulation), and autonomic balance index (ABI - LF/HF). Besides, a stress index (the ratio of stress episode duration to the total task duration) was calculated for each task based on the dynamics of the cardiointervalographic indices.

Parametric and nonparametric methods were used for statistical data analysis: repeated measures ANOVA with Bonferroni correction, Wilcoxon test, Student's t-test, and Spearman correlation analysis.

\begin{tabular}{|c|c|c|c|c|c|c|c|c|c|c|c|}
\hline \multicolumn{4}{|c|}{ Psychophysiological testing } & \multicolumn{4}{|c|}{ Linguistic testing } & \multicolumn{4}{|c|}{ Psychophysiological testing } \\
\hline $\begin{array}{c}\text { Test } \\
\text { for the emotional } \\
\text { disadaptation } \\
\text { level }\end{array}$ & $\begin{array}{c}\text { Computer } \\
\text { campimetry }\end{array}$ & $\begin{array}{l}\text { Sensorimotor } \\
\text { coordination }\end{array}$ & $\begin{array}{c}\text { Stroop } \\
\text { test }\end{array}$ & $\begin{array}{c}\text { Shadowing } \\
\text { in the foreign } \\
\text { language }\end{array}$ & $\begin{array}{l}\text { Interpretation } \\
\text { from the foreign } \\
\text { language }\end{array}$ & $\begin{array}{c}\text { Shadowing } \\
\text { in the native } \\
\text { language }\end{array}$ & $\begin{array}{c}\text { Interpretation } \\
\text { from the native } \\
\text { language }\end{array}$ & $\begin{array}{c}\text { Stroop } \\
\text { test }\end{array}$ & $\begin{array}{l}\text { Sensorimotor } \\
\text { coordination }\end{array}$ & $\begin{array}{l}\text { Computer } \\
\text { campimetry }\end{array}$ & $\begin{array}{c}\text { Test } \\
\text { for emotional } \\
\text { disadaptation } \\
\text { level }\end{array}$ \\
\hline \multicolumn{8}{|c|}{ Audio recording of the performed tasks } & & & & \\
\hline \multicolumn{12}{|c|}{ Event-related telemetry of the heart rate (ERT HR) } \\
\hline
\end{tabular}

Figure 1. Design of the experiment 


\section{Results and Discussion}

The analysis of the native cardiointervalogram dynamics revealed characteristic features of energy supply during linguistic task implementation. In relation to $R-R$ intervals, the significance of the effects associated with the following factors was assessed: "group" (control, pro), "source language" (foreign, native), "task" (shadowing, simultaneous) (Figure 2). Significant effects associated with the "group" factor were detected $(F=19.61 ; p=0.0001)$. The analysis of the native cardiointervalogram dynamics showed a significantly higher level of stress ( $R-R$ intervals are significantly shorter) in simultaneous interpreters relative to the control group only during simultaneous interpretation (see Figure 2).

Characteristically, statistically significant intergroup
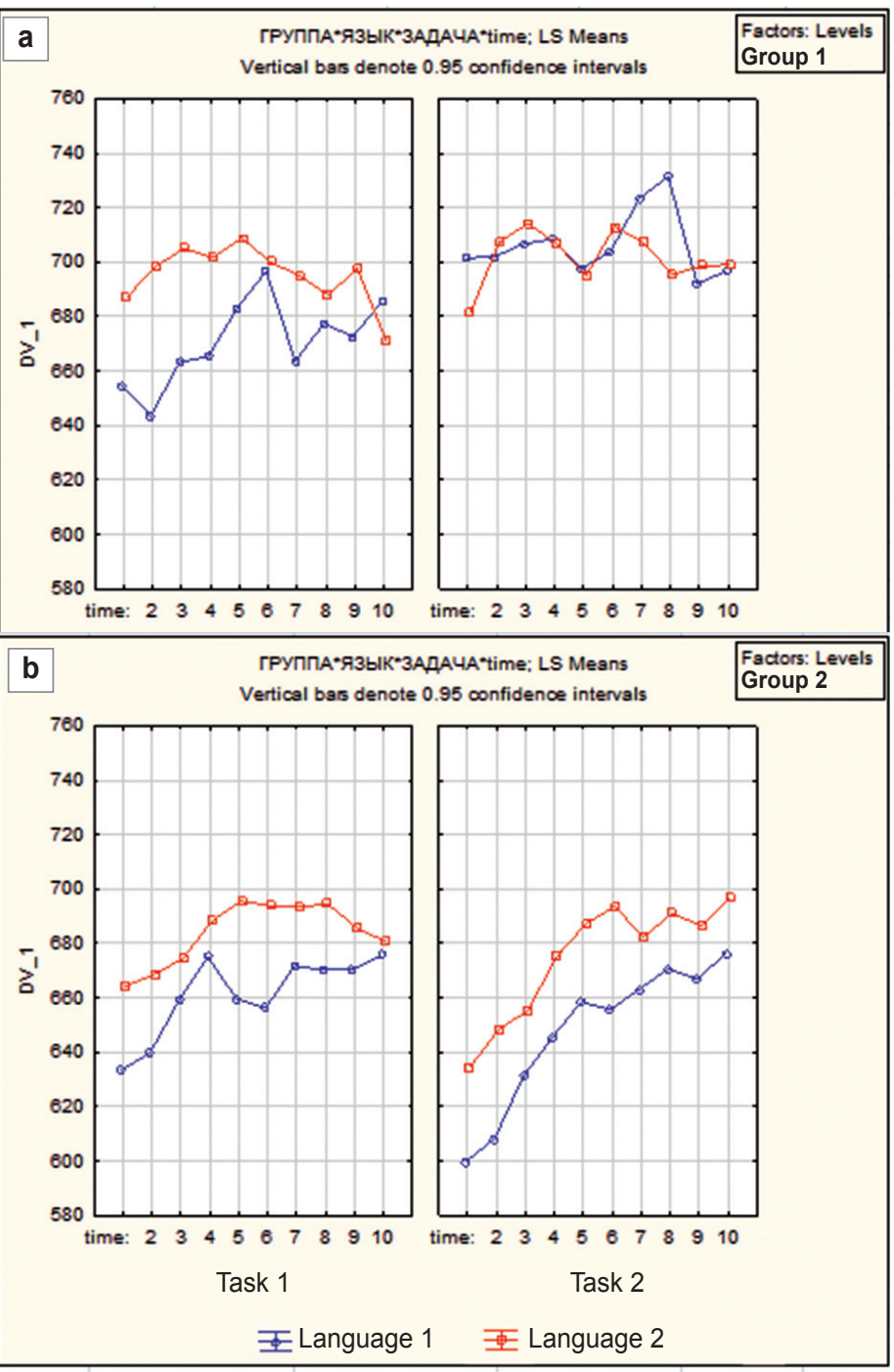

Figure 2. Group-averaged dynamics of participants' R-R intervals in the context of solving linguistic tasks:

(a) group "control"; (b) group "pro"; task 1 - shadowing, task 2 simultaneous translations from the foreign (1, blue) and native (2, red) languages. Division along the time axis $30 \mathrm{~s}$. On $\mathrm{Y}$ axis are averaged $\mathrm{R}-\mathrm{R}$ intervals ( $\mathrm{ms}$ ) over $30 \mathrm{~s}$ differences of $R-R$ intervals during simultaneous interpreting (regardless of the translation direction: native-foreign or foreign-native) were detected at the first $100 \mathrm{~s}$ of the task performance. In the speech shadowing task, no intergroup differences were found in regard to the sources both in the foreign and native language.

Averaging of $\mathrm{R}-\mathrm{R}$ intervals recorded over the whole period of solving the linguistic tasks confirmed the fact that simultaneous interpreters experienced a significantly greater strain during simultaneous interpreting in comparison with the control group (Figure 3). And statistically significant intergroup effects associated with the "task" factor became evident during task performance only in relation to the speech in the target language: in the "control" group, the speech shadowing task was solved at greater energy consumption ( $R-R$ intervals are shorter) than simultaneous interpreting; in the "pro" group, the speech shadowing task was solved at less energy consumption ( $R-R$ intervals are longer) than simultaneous interpreting. Prior to the performance of the linguistic tasks, R-R interval indices in both groups did not differ significantly.

Unexpectedly lower tension of energy resources in the "control" group performing the tasks on simultaneous interpretation only was likely to be due to the utter futility of the task for the participants who knew some foreign language but did not have special skills and experience in simultaneous interpreting. However, according to a hypothesis which is considered to be more grounded, a specific functional system, providing a successful solution of the task on simultaneous interpreting in the "pro" group, has not been formed in the participants of the control group.

While analyzing the calculated indicators of heart rate variability spectrum it has been established that the stress index was significantly lower in simultaneous interpreters relative to the control group during simultaneous interpreting and after the performance of all linguistic tasks (Figure 4).

This result completely satisfies the hypothesis about the absence of a specific functional system for solving the task of simultaneous interpreting in the representatives of the control group resulting in realization of nonspecific protective program, i.e. stress. Besides, this result confirms again the previously obtained data [10-12] about a poor informativity of native R-R interval dynamics for stress detection. A simple reduction of interval duration only signifies the increase of the load and tension, respectively, but is not a sign of stress. At the same time, dynamic modes of calculated cardiointervalographic indicators typical for stress have been reliably verified: a sharp increase of autonomic balance index concurrently with the fall of the total power of the heart rate variability 


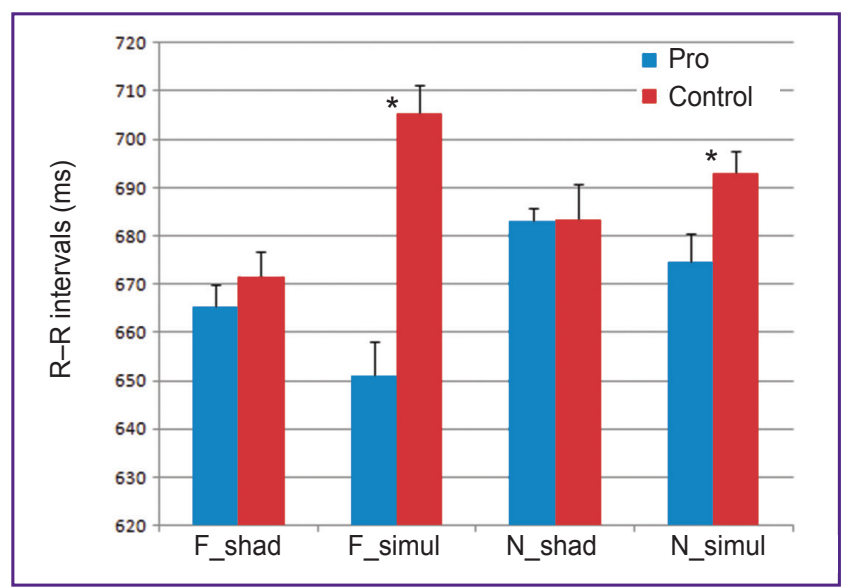

Figure 3. Specificity of the heart rate in simultaneous interpreters and in the control group during linguistic tasks

* Statistically significant differences between the control and experimental groups $(p<0.0001)$ using Bonferroni corrections

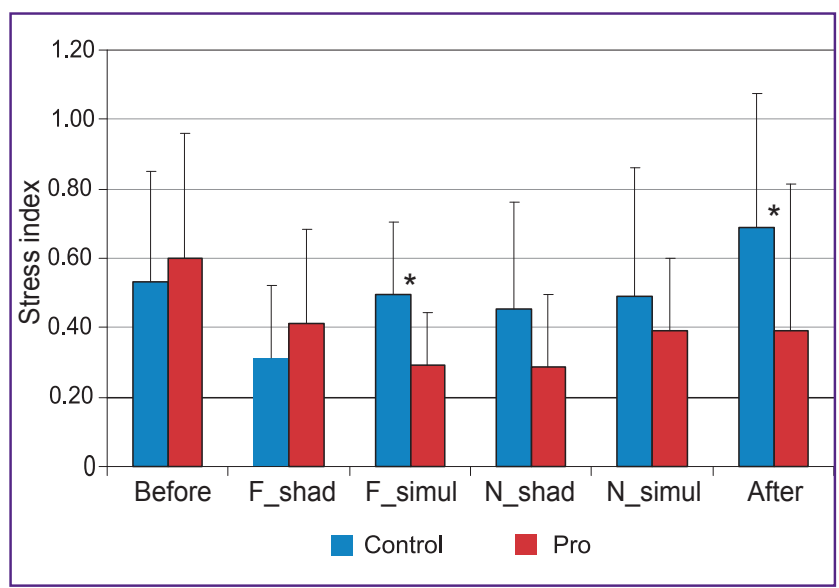

Figure 4. Distribution of the stress index in simultaneous interpreters and the control group before, during, and after the solution of various linguistic tasks

* Statistically significant differences between the control and experimental groups $(p<0.0001)$ using Bonferroni corrections

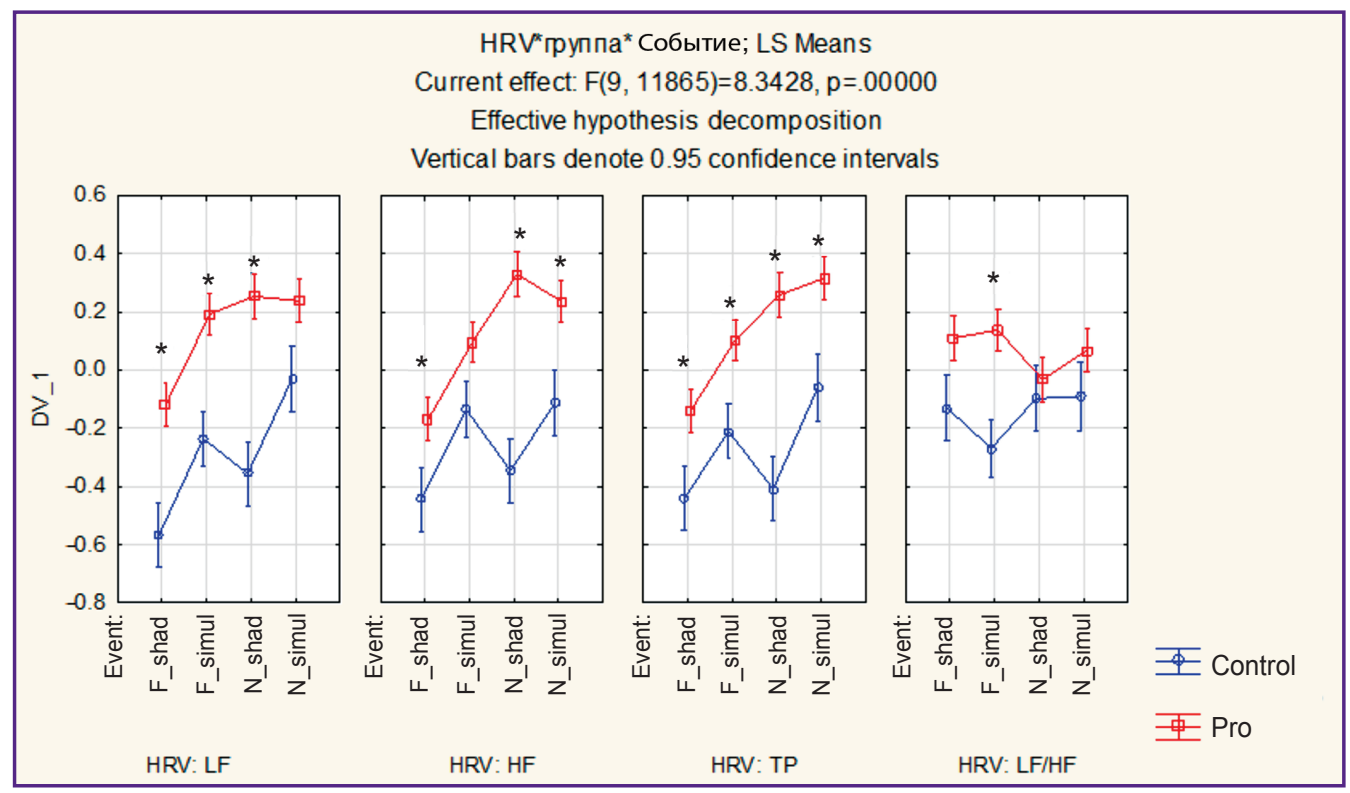

Figure 5. Dynamics of the calculated indicators of heart rate variability spectrum in the experimental and control group during the performance of four linguistic tasks

* Statistically significant differences between the control and experimental groups $(p<0.0001)$ using Bonferroni corrections; $Y$ axis - standardized values relative to the group average

spectrum $[13,14]$. It is this dynamics that marks the beginning of acute stress [15].

The detailed analysis of the heart rate variability spectrum showed that according to the majority of indicators, the activity of the central circuits of the cardiac rhythm control is significantly higher in the experimental group than in the control over the entire period of the linguistic part of the experiment (Figure 5).

The most indicative are the indicators of the total power of the heart rate variability spectrum (TP), i.e. the adaptation potential of the participants. Indices of activity of the sympathetic (LF) and parasympathetic
(HF) regulation circuits are normally higher in the experimental group. The former is known to reflect the intensity of energy resource control enhancing under physical and emotional loads, while the latter is believed to support cognitive loads [12]. At the same time, differences between automatic balance indices (LF/HF) are insignificant: they become statistically significant only during simultaneous interpreting from the foreign to the native language.

Of special attention are questions of distributing the activity of the central circuits of autonomic cardiac rhythm regulation depending on the context: "task" 


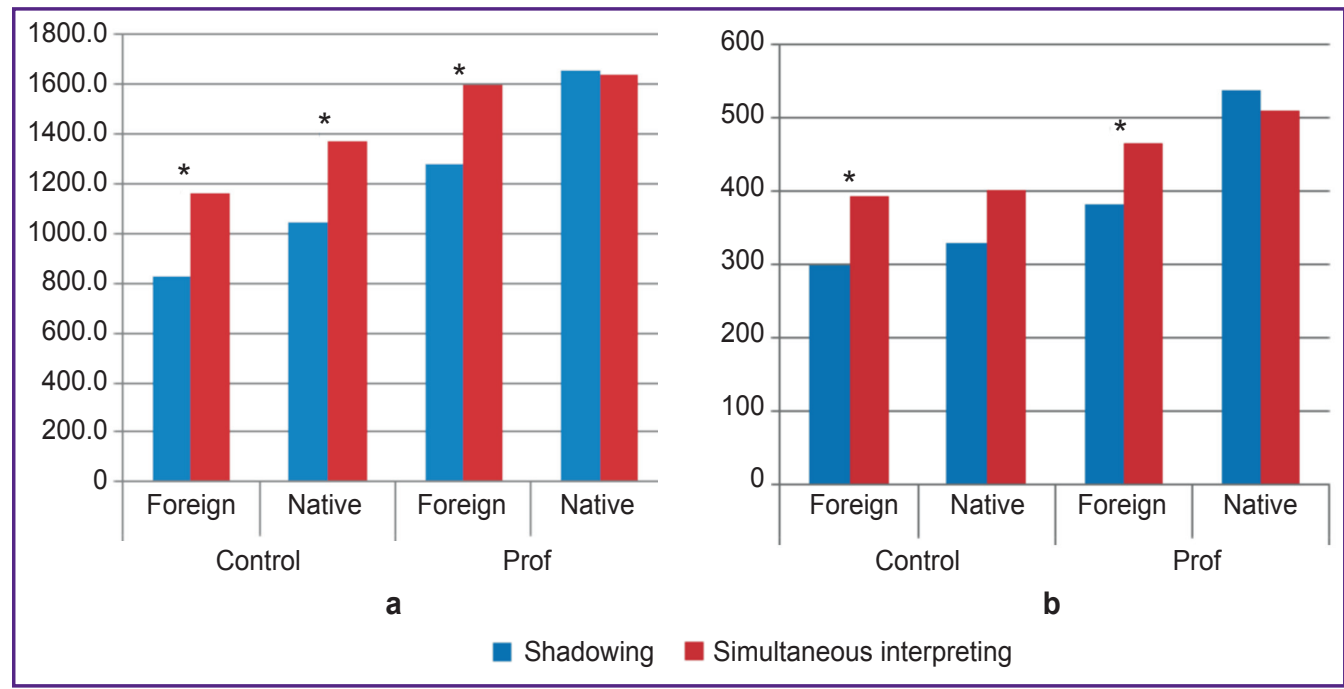

Figure 6. Comparison of some calculated indicators of the heart rate variability spectrum in the control and experimental groups depending on the task character (shadowing - simultaneous interpreting) and the language (native - foreign):

(a) LF, sympathetic regulation circuit; (b) HF, parasympathetic regulation circuit. $Y$ axis $-L F$ and HF values $\left(\mathrm{ms}^{2}\right) .{ }^{*}$ Statistically significant differences between the control and experimental groups $(p<0.0001)$ using Bonferroni corrections

(shadowing, simultaneous translation) or "language" (shadowing in the native language and interpretation from the native language - shadowing in the foreign language and interpretation from the foreign language) (Figure 6). The tasks of simultaneous interpreting predictably caused essentially greater activation of the sympathetic and parasympathetic regulation circuits compared to shadowing. Primarily, it was notable in the work with a foreign language. However, in the control group and in solving the task in the native language, activation of the sympathetic regulation link appeared to be significantly more pronounced during simultaneous interpreting.

Much more prominent differences in the level of organization of the appropriate functional system connected with mastering the simultaneous interpreting technology were found by the correlation analysis of the indicators of the heart rate variability spectrum at all stages of the experiment (Figure 7). If statistically significant $(p<0.5)$ strong $(r>0.7)$ relations for each of spectrum index between all stages of linguistic tasks were characteristic for simultaneous interpreters (Figure 7 (a)) (but without considerable interactions with "before" and "after" stages), in the control group (Figure 7 (b)), a deep disintegration is observed being also a strong argument in favor of the hypothesis about a special significance of the formed specific functional system for realization of the act of simultaneous interpreting.

Psychophysiological tests conducted prior to and after the linguistic tasks allowed us to detect some additional details of the cognitive-affective sphere dynamics during simultaneous interpreting. Thus, according to the results of the projective test for emotional disadaptation level, a slight but statistically significant $(p<0.05)$ increase of the emotional disadaptation level was registered in the experimental group after solving the linguistic tasks while in the control group, these changes were statistically insignificant. In both groups, we failed to find essential changes in the differential level of color-discrimination threshold (computer campimetry test). The results of a simple sensorimotor test demonstrated a statistically significantly lower response speed in simultaneous interpreters prior to and especially after the linguistic tasks but a considerably greater accuracy $(p<0.01)$ which suggests a high level of cognitive control relative to the control group.

This situation was verified in the Stroop test (see the Table). This computerized test simulating a cognitive conflict is, in our opinion, a satisfactory experimental model of the comprehensive cognitive loads making it possible to reproduce different variants of information image (or code) interaction: their consolidation (i.e. alleviation in neural modules) and competition (occlusion in the neural networks).

In both "pro" and "control" groups, the effect of consolidation appears before and after the linguistic tasks: if verbal and sensory color images are identical (task "Color", the color of the letters corresponds to the word meaning) the time of decision-making decreases in regard to the task with black-and-white names of the colors (task "Mono").

Intergroup differences in the interaction of the multimodal color images are found in the tasks with a cognitive conflict: 

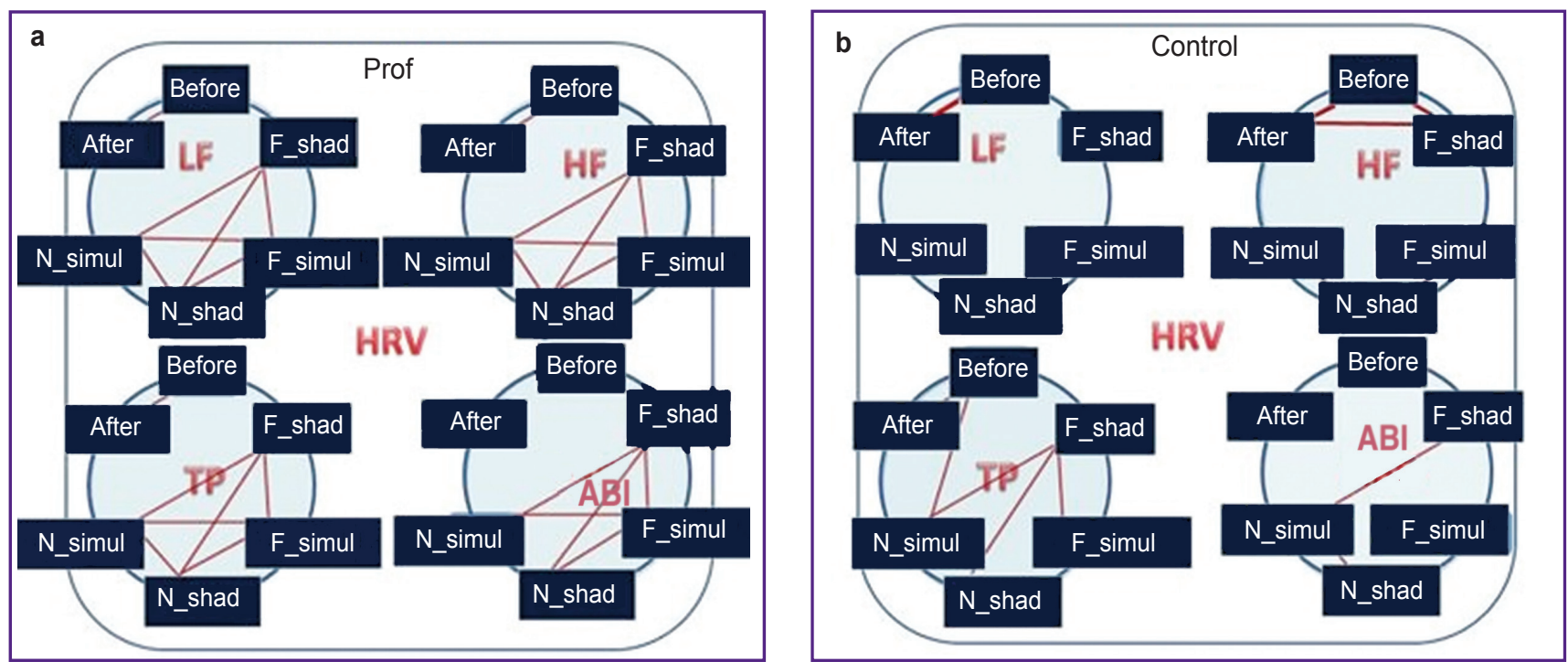

Figure 7. Results of the correlation analysis of the indicators of the heart rate variability spectrum at all stages of the experiment:

(a) in simultaneous interpreters; (b) in the control group. Red lines designate strong $(r>0.7)$ statistically significant relations $(p<0.05)$. HRV — heart rate variability; $A B I-L F / H F$

Group average duration of Stroop test performance (s) before and after the linguistic tasks $(\mathrm{M} \pm \mathrm{m})$

\begin{tabular}{cccccc}
\hline Stage & Group & Mono & Color & True text & True color \\
\multirow{2}{*}{ Before performance } & Prof & $1016.96 \pm 248.70$ & $930.62 \pm 185.63^{*}$ & $1175.48 \pm 373.01^{*}$ & $1158.04 \pm 410.01^{*}$ \\
\cline { 2 - 6 } & Control & $1264.68 \pm 534.20$ & $1071.35 \pm 251.29^{*}$ & $1369.26 \pm 464.02^{*}$ & $1264.68 \pm 534.20$ \\
\multirow{2}{*}{ After performance } & Prof & $985.87 \pm 241.22$ & $921.50 \pm 191.15^{*}$ & $1149.45 \pm 390.36^{*}$ & $1127.19 \pm 471.37^{*}$ \\
\cline { 2 - 6 } & Control & $1356.71 \pm 894.80$ & $1147.83 \pm 714.67^{*}$ & $1453.95 \pm 845.00$ & $1486.52 \pm 889.63^{*}$ \\
\hline
\end{tabular}

* Statistically significant differences between the indices for the task "Mono" $(p<0.05)$.

professional interpreters show the effect of competition prior to and after the linguistic tasks, i.e. disagreement of verbal and sensor images (the color of the word letters does not correspond to the word meaning) increases the time of decision-making in regard to the task with black-and-white names of the colors (task "Mono"), i.e. the selection by the meaning of the word (task "True text", as well as by the color of the letters (task "True color") becomes difficult;

in the control group, inversion of competition effects is observed prior to and after the linguistic tasks: prior to the linguistic tasks, selection by the word meaning (task "True text") is impeded i.e. a sensor image inhibits the realization of the verbal image; after the linguistic tasks, selection by the letter color is impeded, i.e. the verbal image inhibits realization of the sensor one.

Enhancement of the verbal images is likely to occur in the control group after the linguistic tasks whereas the activity of the sensor images is reduced. It allows shadowing and simultaneous interpreting to be considered as an effective training of linguistic functions.

\section{Conclusion}

The conducted study allowed us to discover some specific aspects of autonomic provision of simultaneous interpreting. Firstly, a significantly greater strain of the autonomic regulation is manifested by the simultaneous interpreters compared to the control group. It was most prominent when translation was done from the foreign language. Secondly, the total level of stress during linguistic tasks appeared to be higher in the control group. Thirdly, in the simultaneous interpreters, in contrast to the control group, there was registered a high activity level of the sympathetic and parasympathetic systems and a marked integration of the cardiac rhythm regulation circuits over the entire period of linguistic tasks. Fourthly, the psychological tests have demonstrated a significantly more confident cognitive control relative to the control group. These results are serious arguments in favor of the hypothesis that simultaneous interpreters possess a formed specific functional system providing a successful interaction of various information codes (or images) and, 
consequently, consolidation of autonomic and cognitive resources when performing professional tasks. Lack of the necessary skills and, therefore, a special taskoriented functional system in the participants of the control group result in the enhancement of the nonspecific (less effective) stress response.

Study funding. The work was partly supported by the Russian Foundation of Basic Research (grants No.1606-00501_a, 18-013-01225_a, 18-413-520006_p_a, 19013-00095_a).

Conflicts of interest. The authors have no conflicts of interest to declare.

\section{References}

1. Pöchhacker F. Introducing interpreting studies Routledge; 2004, https://doi.org/10.4324/9780203504802.

2. Moser-Mercer $\mathrm{B}$. Remote interpreting: the crucial role of presence. Bulletin VALS-ASLA (Swiss association of applied linguistics) 2005; 81: 73-97.

3. Gile D. Effort models. In: Routledge encyclopedia of interpreting studies. Pöchhacker F. (editor). Routledge; 2015; p. 135-137.

4. Hervais-Adelman A., Moser-Mercer B., Michel C.M., Golestani N. fMRI of simultaneous interpretation reveals the neural basis of extreme language control. Cerebral Cortex 2014; 25(12): 4727-4739, https://doi.org/10.1093/cercor/bhu158.

5. Elmer S., Kühnis J. Functional connectivity in the left dorsal stream facilitates simultaneous language translation: an EEG study. Front Hum Neurosci 2016; 10: 60, https://doi. org/10.3389/fnhum.2016.00060.

6. Korpal P. Interpreting as a stressful activity: physiological measures of stress in simultaneous interpreting. Poznan Studies in Contemporary Linguistics 2016; 52(2): 297316, https://doi.org/10.1515/psicl-2016-0011.
7. Chernigovskaya T.V., Parin S.B., Parina I.S., Konina A.A., Urikh D.K., Yachmonina Y.O., Chernova M.A., Polevaya S.A. Simultaneous interpreting and stress: pilot experiment. Int J Psychophysiol 2016; 165, https://doi. org/10.1016/j.ijpsycho.2016.07.472.

8. Shishalov I.S., Polevaya S.A., Parin S.B., Kozhevnikov V.V., Nekrasova M.M., Bakhchina A.V., Kovalchuk A.V. The system for determining the functional state of a group of people. Patent RU 129680. 2013.

9. Grigoryeva V.N., Tkhostov A.Sh. Method for estimating human emotional state. Patent RU 2291720. 2007.

10. Runova E.V., Grigoreva V.N., Bakhchina A.V., Parin S.B., Shishalov I.S., Kozhevnikov V.V., Nekrasova M.M., Karatushina D.I., Grigoreva K.A., Polevaya S.A. Vegetative correlates of conscious representation of emotional stress. Sovremennye tehnologii v medicine 2013; 5(4): 69-77.

11. Parin S.B., Vetyugov V.V., Bakhchina A.V., Polevaya S.A. The role of the endogenous opioid system in the control of heart rate variability under cognitive loads of various levels. Sovremennye tehnologii v medicine 2014; 6(4): $116-126$.

12. Baevsky R.M., Berseneva A.P. Pre-nosology diagnostics. Cardiometry 2017; 10: 55-63, https://doi. org/10.12710/cardiometry.2017.10.5563.

13. Bakhchina A.V., Shishalov I.S., Parin S.B. Polevaya S.A. The dynamic cardiovascular markers of acute stress. Int J Psychophysiol 2014; 94(2): 230, https://doi. org/10.1016/j.ijpsycho.2014.08.899.

14. Parin S., Polevaia S., Gromov K., Polevaia A., Kovalchuk A. Short-term variability of $R-R$ intervals during acute stress in healthy adults: neuromorphic model, experiment data, monitoring of daily life activity. Int $J$ Psychophysiol 2016; 108: 88, https://doi.org/10.1016/j. ijpsycho.2016.07.276.

15. Nekrasova M.M., Polevaya S.A., Parin S.B., Shishalov .S., Bakhchina A.V. Method for diagnosing stress. Patent RU 2531443. 2014. 